\title{
An Anatomy Massive Open Online Course as a Continuing Professional Development Tool for Healthcare Professionals
}

\author{
James D Pickering ${ }^{1,2} \cdot$ Bronwen J Swinnerton ${ }^{2}$
}

Published online: 12 February 2017

(C) The Author(s) 2017. This article is published with open access at Springerlink.com

\begin{abstract}
Massive open online courses (MOOCs) remain a novel and under-evaluated learning tool within anatomical and medical education. This study aimed to provide valuable information by using an anatomy MOOC to investigate the demographic profile, patterns of engagement and selfperceived benefits to healthcare professionals. A 21 -item survey aimed at healthcare professionals was embedded into the Exploring Anatomy: The Human Abdomen MOOC, in April 2016. The course attracted 2711 individual learners with 94 of these completing the survey, and 79 of those confirming they worked full- or part-time as healthcare professionals. Variations in use across healthcare profession (allied healthcare professional, nurse or doctor) were explored using a Fisher's exact test to calculate significance across demographic, motivation and engagement items; one-way ANOVA was used to compare self-perceived benefits. Survey data revealed that $53.2 \%$ were allied healthcare professionals, $35.4 \%$ nurses and $11.4 \%$ doctors. Across all professions, the main motivation for enrolling was to learn new things in relation to their clinical practice, with a majority following the prescribed course pathway and utilising core, and clinically relevant, material. The main benefits were in relation to improving anatomy knowledge, which enabled better support for patients. This exploratory study assessing engagement and self-perceived benefits of an anatomy MOOC
\end{abstract}

James D Pickering

j.d.pickering@leeds.ac.uk

1 Division of Anatomy, Leeds Institute of Medical Education, School of Medicine, University of Leeds, Leeds, UK

2 Research Centre in Digital Learning, School of Education, University of Leeds, Leeds, UK has shown a high level of ordered involvement, with some indicators suggesting possible benefits to patients by enhancing the subject knowledge of those enrolled. It is suggested that this type of learning tool should be further explored as an approach to continuing professional, and interprofessional, education.

Keywords Massive open online course · Continuing professional development $\cdot$ Interprofessional education . Online learning $\cdot$ Medical education

\section{Introduction}

Massive open online courses (MOOCs) have recently been proposed to revolutionise education; however, the initial enthusiasm has abated and their role is now under considerable debate [1-3]. Within medical, and recently anatomical, education, there have been numerous suggestions as to how MOOCs can influence healthcare professional's training without, as yet, any substantial empirical evidence to develop a conceptual framework for their wider implementation [4-7]. However, what is clear from the wider literature is that computer-based instruction is effective in supporting learning if appropriately designed $[8,9]$; but with so many different forms, it is unclear which format suits which learning context $[5,10]$. Online learning per se is not a novel educational modality, with existing forms typically involving an individual learner navigating content in effective isolation [11]. MOOCs, in contrast, are open and accessible to large numbers of learners from diverse backgrounds, with the only restrictive factor being access to an internet-enabled electronic device. Typically, MOOCs are based around conventional higher education programmes and integrate video-based lecture material, automated online assessments, and discussion fora for 
learners to engage with in a personalised manner that suits their individual needs. This informal, voluntary approach to learning is different to how many healthcare professionals would have previously learned, which is tutor driven and assessment based, with the drive to learn often based upon assessments [12-15]. Due to the absence of a highly scaffolded curriculum, and only a suggested course pathway to guide learners, a high degree of self-regulation is required to optimise the MOOC learning experience [16-20]. Concomitant with the ability to acquire or refresh knowledge, MOOCs provide a platform for collaboration amongst a heterogeneous population of learners [21], enabling the sharing of experiences and development of ideas beyond the material provided. The potential for this interchange of ideas within MOOCs is highly applicable to medical education due to the constant need for healthcare professionals to develop and discover new knowledge. Across undergraduate and postgraduate medical education, MOOCs have an emerging presence with evidence to support their use as part of blended curricula on campus-based medical course [7], suggestions they could be used as part of flipped classroom approaches [22-24], although research from other disciplines suggests this needs serious consideration [25]. Additionally, they have been suggested as an alternative platform for interprofessional education (IPE) [26] or as an online approach to continuing professional development (CPD) [6, 27-32].

Previous research using the same MOOC detailed in this study highlighted a mixed uptake by undergraduate medical students [7]. In this specific context, the MOOC was used as a supplementary tool as part of a blended learning curriculum that included a range of teacher-led sessions (i.e. lectures, dissection classes and tutorials), and self-directed resources embedded into the course's virtual learning environment (i.e. formative assessment, practical class videos, eBooks, and social media channel). Assessing the impact on students who engaged with the MOOC revealed that a clear majority were in favour, which is generally supported by the literature [33-35], but not at the expense of replacing the existing teacher-led sessions. Moreover, the undergraduate students used the MOOC in a personalised manner and engaged with the specific resources which they determined were of benefit to them. This is not a surprising pattern of behaviour given that they were enrolled on a medical course which has a clearly defined curriculum. Although there are clear advantages to integrating the existing content of MOOCs into campusbased undergraduate courses, due to the financial and temporal demands required to develop a MOOC the main rationale for their further development needs to be focused on offcampus education.

Continual professional development programmes are an important part of healthcare professional's postgraduate training and serve to maintain and improve an individual's performance in relation to patient outcomes [36]. Developing CPD programmes is particularly pertinent within anatomical education due to its diminishing presence within broadening medical curricula [37-39]. Currently, numerous approaches to remedy this potential shortfall in anatomy knowledge have been proposed, including: demonstrating and teaching assistantship schemes [40], the creation of postgraduate training centres and the development of specific postgraduate anatomy qualifications, such as the Diploma in Surgical Anatomy run by the University of Dunedin in New Zealand [41]. Moreover, across medical education, there remains a need to explore the distinction between core knowledge, which is suitable for undergraduate students, and advanced knowledge, which is intended for specialist trainees [42]. As healthcare professional's roles become more specialised, it is important that opportunities are afforded which allow individuals the option to personalise their learning - that is, an ability to select the specific learning objects required for an individual's exact requirement. Although anatomy training at postgraduate level requires a hands-on approach to acquire both the advanced knowledge and to develop the necessary skill set, MOOCs may provide an opportunity for all healthcare professionals, whatever their level of training and location, to engage in a form of CPD that allows them to increase their knowledge base. Moreover, due to the heterogeneous population of healthcare professionals who can engage in the course simultaneously, MOOCs have the potential to support IPE in an online setting [26]. This is particularly timely with the increased drive to utilise IPE across healthcare curricula, and especially within the basic sciences such as anatomy [26, 43, 44]. It is well understood that IPE is an important approach to medical training, which intends to highlight the changing nature of clinical practice, and improve patient outcomes [43]. With the growing demand for IPE across medical curricula, the use of technology is a possibility for supporting its introduction and allow healthcare professionals an opportunity to contextualise their learning within the clinical setting as part of an interprofessional team. Technology, and potentially MOOCs, can provide an online platform for healthcare professionals from a range of specialties to collaborate and learn with each other across boundaries [26, 43].

Currently, although much is known about the demographic profile of MOOC learners [21], measuring their actual impact is difficult. For example, interpretation of completion rates is difficult without knowing the motivations of the individual learners, and although MOOCs are known for their massiveness, within the abundance of data and statistics, there are invisible learners who will be on a personal journey that is specific to them [45]. Each of these individual learners will have their own specific goals, and attempting to measure the success, or otherwise, of MOOCs across broad profiles is particularly difficult, and perhaps unhelpful. Therefore, understanding the impact of MOOCs on these learners is the key to understanding their potential role and scalability. Within medical education, little is understood about the demographic profile, motivations, engagement patterns and perceived benefit 
of MOOCs to healthcare professionals. This exploratory study assesses the use of an anatomy MOOC by healthcare professionals and builds on previous work which focused on undergraduate students use as part of a blended learning medical anatomy curriculum. Questionnaire data is used from learners who self-identified as a healthcare professional to better understand the role of an anatomy MOOC in supporting professional development via the following research questions:

1. What are the demographic profiles of healthcare professionals who enrol on an anatomy MOOC?

2. What patterns of engagement do they exhibit?

3. What are the perceived benefits of the MOOC within clinical practice?

\section{Methods}

\section{Participants and Context}

Healthcare professionals who enrolled on Exploring Anatomy: The Human Abdomen MOOC were directed to a survey via a message posted at the end of week review. The MOOC was developed by the University of Leeds, UK, and hosted on the FutureLearn platform (www.futurelearn.com/ courses/anatomy). The structure and content of the course has been described in detail elsewhere [7]; briefly, the course ran for 3 weeks in April 2016 and covered the clinical anatomy of the abdomen. Each week contained a series of video lectures, automated self-assessment questions, and research and discussion fora. The course attracted 2711 individual learners, with the majority of learners on the course not identifying as healthcare professionals; of the 138 who identified as working in the health and social care sector, 94 (68. $1 \%$ ) completed this additional survey.

\section{Instrument, Data Handling and Statistical Analysis}

Of the 94 individuals, 15 were removed as they failed to identify as being in either full-time or part-time employment leaving 79 who were analysed further. The survey instrument contained 21 questions in line with the study's research questions with one of these requiring the learners to confirm consent. Five questions sought to obtain demographic data, specifically: gender, age, highest qualification, employment status and current role. The remaining items focused on motivation (3 questions), engagement (5 questions) and selfperceived benefits ( 7 questions). To determine statistical significance for the type of role against the demographic, motivation and engagement items, Fisher's exact test was implemented due to some contingency table cells containing values $<5$. The 4 questions that focused on the perceived benefits of the course were positively phrased Likert-style and presented as mean $(\mathrm{M}) \pm$ standard deviation (SD) of the mean, with the percentage of students agreeing with statements also detailed in the text where appropriate [46]. Furthermore, to determine any statistical difference across healthcare role the individual responses (strongly agree, 5; agree, 4; neither agree nor disagree, 3 ; disagree, 2; strongly disagree, 1), the perceived benefit questions were summed with a minimum and maximum score of 4 and 20, respectively, possible, and one-way ANOVA deployed. The summed scores are presented as the mean and standard deviation with an alpha level of 0.05 used to determine statistical significance. The internal reliability of these four items within the instrument was good with a Cronbach's alpha of 0.86 , and the whole instrument calculated as 0.71 . The final item asked participants to provide an example as to how completing the anatomy MOOC has enhanced your clinical work? Individual learner responses were coded (AHP = allied health professional; $\mathrm{D}=$ doctor; $\mathrm{N}=$ nurse $)$ and randomly assigned a learner identification number (i.e. D2). Comments were assigned to one of two emergent themes which were determined and confirmed by both authors, and presented verbatim within the results section. Four comments were removed as not relevant. The survey was administered using Bristol Online Survey (www.onlinesurveys.ac.uk) with learner responses downloaded to an Excel document (Microsoft Excel 2015, version 15.14, Microsoft Corp., Redmond, WA) and analysis performed in Statistical Package for Social Sciences, version 22 (IBM Corp., Armonk, NY).

\section{Results}

\section{Learner Demographics}

From the learners who completed the survey, 54 (68.4\%) and $25(31.6 \%)$ self-identified as female or male, respectively $(P<0.05)$, with $42(53.2 \%)$ working as an AHP, $9(11.4 \%)$ as a doctor and $28(35.4 \%)$ as a nurse $(P<0.05)$. Of those who work in allied healthcare, there were a higher proportion of females compared to males ( $66.7 \%$ vs $33.3 \%)$, with roles such as occupational therapist, radiographer, dietician and paramedic identified. Similarly, there were a larger number of females amongst those who self-identified as nurses $(82.1 \%$ vs $17.9 \%$ ), with staff nurse, surgical nurse specialist and practice nurse being common roles. The remaining learners selfidentified as doctors with the majority being male $(66.6 \%$ vs $33.3 \%$ ), and roles such as paediatric surgeon and general practitioner being reported.

The remaining demographic data is detailed in Table 1 and reveals the age, highest qualification and employment status. The age of the group as a whole was evenly distributed with the highest number of learners within the 46-55 years of age 
Table 1 Demographic information for the healthcare professionals

\begin{tabular}{|c|c|c|c|c|c|}
\hline & Total $(\%)$ & Allied health professional (\%) & Doctor $(\%)$ & Nurse $(\%)$ & Fisher's test \\
\hline \multicolumn{6}{|l|}{ Age of learner } \\
\hline 18-25 years of age & $9(11.4)$ & $5(11.9)$ & $2(22.2)$ & $\begin{array}{l}2(7.1) \\
5(179)\end{array}$ & \multirow[t]{6}{*}{$P>0.0$} \\
\hline $26-35$ years of age & $15(19.0)$ & $8(19.0)$ & $2(22.2)$ & $5(17.9)$ & \\
\hline $36-45$ years of age & $17(21.5)$ & $7(16.7)$ & $3(33.3)$ & $7(25.0)$ & \\
\hline $46-55$ years of age & $24(30.4)$ & $12(28.6)$ & $1(11.1)$ & $11(39.3)$ & \\
\hline $56-65$ years of age & $12(15.2)$ & $8(19.0)$ & $1(11.1)$ & $3(10.7)$ & \\
\hline 66 years of age and over & $2(2.5)$ & $2(4.80$ & $0(0.0)$ & $0(0.0)$ & \\
\hline \multicolumn{6}{|l|}{ Highest qualification } \\
\hline Less than high school or secondary education & $2(2.5)$ & $2(4.8)$ & $0(0.0)$ & $0(0.0)$ & \multirow[t]{5}{*}{$P>0.0$} \\
\hline High school or secondary education & $18(22.8)$ & $12(28.6)$ & $0(0.0)$ & $6(21.4)$ & \\
\hline University/college (degree level) & $44(55.7)$ & $20(47.6)$ & $5(55.6)$ & $19(67.9)$ & \\
\hline University/college (masters level) & $11(13.9)$ & $5(11.9)$ & $3(33.3)$ & $3(10.7)$ & \\
\hline University/college (doctorate level) & $4(5.1)$ & $3(7.1)$ & $1(11.1)$ & $0(0.0)$ & \\
\hline \multicolumn{6}{|l|}{ Employment status } \\
\hline Working full time (35 or more hours per week) & $53(67.1)$ & $26(61.9)$ & $8(88.9)$ & $19(67.9)$ & \multirow[t]{2}{*}{$P>0.05$} \\
\hline Working part time (less than $35 \mathrm{~h}$ per week) & $26(32.9)$ & $16(38.1)$ & $1(11.1)$ & $9(32.1)$ & \\
\hline
\end{tabular}

range for all healthcare roles. In regard to highest qualification, over half the group were educated to the degree level, with a slightly larger proportion stated they were in full-time employment.

\section{Motivations for Enrolling on the Anatomy MOOC}

Table 2 outlines the motivations for enrolling on to the MOOC and highlights that the vast majority of learners were motivated to learn new things, with this specifically being in relation to their clinical work. However, it should be noted that the healthcare professionals who had self-identified as doctors were significantly more motivated to take the MOOC so they could engage with university-level education and to supplement their existing studies, although this latter aspect did not reach significance $(P>0.05)$. In addition, a majority would have enrolled even if it was unrelated to their clinical work, with this being lowest amongst doctors.

\section{Engagement with the Anatomy MOOC}

How learners engaged with the MOOC in regards to following the course pathway, utilisation of resources, location and level of interaction were assessed and presented in Table 3. Overall, $80 \%$ of healthcare professionals followed the suggested course pathway to a high degree (completely or mostly), with the vast

Table 2 Motivations for enrolling on to the MOOC

\begin{tabular}{|c|c|c|c|c|c|}
\hline & $\begin{array}{l}\text { Total } \\
(\%)\end{array}$ & $\begin{array}{l}\text { Allied health professional } \\
(\%)\end{array}$ & $\begin{array}{l}\text { Doctor } \\
(\%)\end{array}$ & $\begin{array}{l}\text { Nurse } \\
(\%)\end{array}$ & $\begin{array}{l}\text { Fisher's } \\
\text { test }\end{array}$ \\
\hline \multicolumn{6}{|l|}{ Why did you enrol on to the Anatomy MOOC? ${ }^{\mathrm{a}}$} \\
\hline To learn new things & $61(78.2)$ & $36(85.7)$ & $3(37.5)$ & $22(78.6)$ & \multirow[t]{3}{*}{$P<0.05$} \\
\hline To try online learning for the first time & $4(5.1)$ & $2(4.8)$ & $0(0.0)$ & $2(7.1)$ & \\
\hline To engage with university level education & $13(16.7)$ & $4(9.5)$ & $5(62.5)$ & $4(14.3)$ & \\
\hline \multicolumn{6}{|l|}{ Why did you enrol on to the anatomy MOOC, specifically? } \\
\hline To learn new things about the body & $13(16.5)$ & $9(21.4)$ & $0(0.0)$ & $4(14.3)$ & \multirow[t]{3}{*}{$P>0.05$} \\
\hline $\begin{array}{l}\text { To further my understanding of the body in relation to my clinical } \\
\text { work }\end{array}$ & $53(67.1)$ & $28(66.7)$ & $5(55.6)$ & $20(71.4)$ & \\
\hline To supplement my existing studies & $13(16.5)$ & $5(11.9)$ & $4(44.4)$ & $4(14.3)$ & \\
\hline \multicolumn{6}{|c|}{ Would you have enrolled on the MOOC if it was unrelated to your area of clinical work? } \\
\hline Yes & $53(67.1)$ & $26(61.9)$ & $5(55.6)$ & $22(78.6)$ & \multirow[t]{2}{*}{$P>0.05$} \\
\hline No & $26(32.9)$ & $16(38.1)$ & $4(44.4)$ & $6(21.4)$ & \\
\hline
\end{tabular}

${ }^{\text {a }}$ To interact with other people received no responses and has been removed from the table 
Table 3 Engagement with the MOOC

\begin{tabular}{|c|c|c|c|c|c|}
\hline & $\begin{array}{l}\text { Total } \\
(\%)\end{array}$ & $\begin{array}{l}\text { Allied health } \\
\text { professional }(\%)\end{array}$ & $\begin{array}{l}\text { Doctor } \\
(\%)\end{array}$ & $\begin{array}{l}\text { Nurse } \\
(\%)\end{array}$ & $\begin{array}{l}\text { Fisher's } \\
\text { test }\end{array}$ \\
\hline \multicolumn{6}{|c|}{ I followed the suggested pathway through the course $\mathrm{a}^{\mathrm{a}}$ : } \\
\hline Completely & $36(45.6)$ & $19(45.2)$ & $5(55.6)$ & $12(42.9)$ & \multirow[t]{3}{*}{$P>0.05$} \\
\hline Mostly & $32(40.5)$ & $17(40.5)$ & $3(33.3)$ & $12(42.9)$ & \\
\hline Somewhat & $11(13.9)$ & $6(14.3)$ & $1(11.1)$ & $4(14.3)$ & \\
\hline \multicolumn{6}{|c|}{ Which aspects of the MOOC did you find most useful for your clinical work? } \\
\hline Introductory lectures & $3(3.8)$ & $3(7.3)$ & $0(0.0)$ & $0(0.0)$ & \multirow[t]{5}{*}{$P>0.05$} \\
\hline Core lectures & $45(57.7)$ & $24(58.5)$ & $2(22.2)$ & $19(67.9)$ & \\
\hline Advanced materials & $10(12.8)$ & $5(12.2)$ & $3(33.3)$ & $2(7.1)$ & \\
\hline Clinical case videos & $19(24.4)$ & $9(22.0)$ & $4(44.4)$ & $6(21.4)$ & \\
\hline $\begin{array}{l}\text { Discussion and comments } \\
\text { sections }\end{array}$ & $1(1.3)$ & $0(0.0)$ & $0(0.0)$ & $1(3.6)$ & \\
\hline \multicolumn{6}{|c|}{ Where did you mainly do the MOOC? } \\
\hline At work & $10(12.8)$ & $5(12.2)$ & $1(11.1)$ & $4(14.3)$ & \multirow[t]{3}{*}{$P>0.05$} \\
\hline At home & $66(84.6)$ & $35(85.4)$ & $7(77.8)$ & $24(85.7)$ & \\
\hline $\begin{array}{l}\text { Travelling, on a mobile } \\
\text { device }\end{array}$ & $2(2.6)$ & $1(2.4)$ & $1(11.1)$ & $0(0.0)$ & \\
\hline \multicolumn{6}{|c|}{ How often did you visit the MOOC? } \\
\hline More than once a day & $15(19.0)$ & $8(19.0)$ & $0(0.0)$ & $7(25.0)$ & \multirow[t]{4}{*}{$P<0.05$} \\
\hline Once a day & $13(16.5)$ & $7(16.7)$ & $2(22.2)$ & $4(14.3)$ & \\
\hline Once every $2-3$ days & $36(45.6)$ & $18(42.9)$ & $2(22.2)$ & $16(57.1)$ & \\
\hline Once a week & $15(19.0)$ & $9(21.4)$ & $5(55.6)$ & $1(3.6)$ & \\
\hline \multicolumn{6}{|c|}{ On average, how long did you spend engaged with the MOOC per visit? } \\
\hline $0-30 \mathrm{~min}$ & $8(10.1)$ & $4(9.5)$ & $2(22.2)$ & $2(7.1)$ & \multirow[t]{4}{*}{$P>0.05$} \\
\hline $30-60 \mathrm{~min}$ & $28(35.4)$ & $17(40.5)$ & $3(33.3)$ & $8(28.6)$ & \\
\hline $60-90 \mathrm{~min}$ & $28(35.4)$ & $10(23.8)$ & $4(44.4)$ & $14(50.0)$ & \\
\hline $90+\min$ & $15(19.0)$ & $11(26.2)$ & $0(0.0)$ & $4(14.3)$ & \\
\hline
\end{tabular}

${ }^{\text {a }}$ Not really and not at all received no response and have been removed from the table majority rating the core lectures and then the clinical case videos as the most useful resource in relation to their clinical work. The only variation amongst role was with doctors who appeared to use the clinical case videos more, although this did not reach significance $(P>0.05)$. In regard to location, the majority accessed the MOOC while at home.

In regard to the temporal engagement, almost 50\% visited the MOOC once every 2-3 days. This was reflected amongst those who self-identified as AHPs and nurses, with doctors engaging significantly less frequently. When accessing the MOOC, the majority engaged for between 30 and $90 \mathrm{~min}$ at a time, with once again those who self-identified as doctors appearing to engage slightly differently with a lower time spent per visit.

To assess the role of, and engagement with, the automated tests and discussion fora located throughout each week of the MOOC, two items posed positively phrased statements: I used the tests located throughout the MOOC to assess how I was progressing during the course and I actively participated in the discussion and research questions to support my learning. Overall, 76 (96.2\%) agreed that the tests supported their progression through the course, which was similar across individual healthcare roles (AHP $=97.6 \%, \mathrm{D}=88.9 \%, N=96.4 \%$ ). In regard to the discussion fora, only $21(26.6 \%)$ agreed that it supported their learning, with doctors $(33.3 \%)$ and nurses (32.1\%) appearing to appreciate them significantly more than AHPs $(21.4 \% ; P<0.05)$.

\section{Perceived Benefits of the Anatomy MOOC}

In regard to the perceived benefits of enrolling, four positively phrased items were added to the questionnaire with the learners asked to express their level of agreement (Fig. 1). All four items were responded to positively indicating that the MOOC was a useful learning tool compared to other resources available $(96.2 \%)$, it advanced the learners understanding of anatomy in relation to their clinical practice (96.2\%), and that they are now more able to work competently (70.5\%) and with increased confidence (79.5\%). To compare responses across the specific healthcare roles, the four items were summed with an overall high level of benefit observed $(\mathrm{M}=16.8, \mathrm{SD}=2.3$ ), with no significant difference amongst 


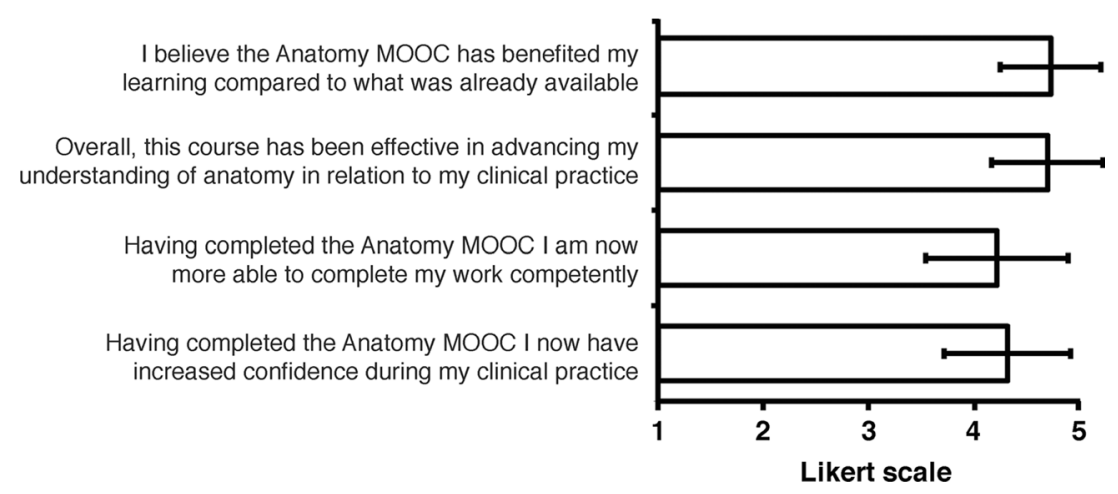

Fig. 1 Quantitative data for the self-perceived benefits of enrolling onto the MOOC for healthcare professionals. Data is presented as mean \pm standard deviation of the mean. Likert scale: 1 strongly

individual roles (AHPs, $\mathrm{M}=16.6, \mathrm{SD}=2.4 ; \mathrm{D}, \mathrm{M}=16.1$, $\mathrm{SD}=1.9 ; \mathrm{N}, \mathrm{M}=17.6, \mathrm{SD}=2.0 ; P>0.05)$.

Qualitative feedback was also obtained with $51(64.6 \%$; $\mathrm{AHP}=52.9 \%$, doctor $=9.8 \%$, nurse $=37.3 \%$ ) healthcare professionals providing further information on how they perceived the MOOC to enhance their clinical practice. Analysing the data revealed two emergent themes: improved anatomy knowledge ( $45.1 \%$ of comments) and improved anatomy knowledge to support patients ( $47.1 \%$ of comments). For example, AHPs and nurses commented: 'I have greater understanding of the gastrointestinal tract' [AHP65], 'I have a better understanding of the inguinal canal' [AHP79], '...more confident when doing abdominal examination' [N38] and 'I now know the exact positions of the abdominal organs' [N59] in regard to improving their understanding of basic abdominal anatomy. In relation to supporting patients, AHPs and nurses commented: 'in MDT (multidisciplinary team) discussions I understand more about the results of CT scans and MRIs' [N2], 'better able to explain clearly to patients about their condition and greater understanding of the procedures they have undergone' [N5], 'actually understand the surgical techniques used in hernia patients under my care' [AHP6] and ' ... more confident if a patient was to ask me about gallstones' [AHP43]. Learners who self-identified as doctors only provided a limited number of comments, including: ' ... refreshed my knowledge' [D72], 'appreciation of anatomy in respect to hernia repair' and 'I am able to provide better clinical mentorship to colleagues and students on clinical placement' [D2].

\section{Discussion}

The use of MOOCs in anatomical and medical education is currently an under evaluated area of pedagogy, with only an emerging evidence base to support the wider integration into relevant undergraduate or postgraduate curricula. Although MOOCs have been available for almost a decade, and courses continually becoming available on disagree, 2 disagree, 3 neither agree nor disagree, 4 agree, 5 strongly agree. Number of participants, $n=79$; Cronbach's alpha $=0.86$

commercial platforms, there remains a paucity of empirical evidence to support their utilisation. Specifically, within medical education, numerous roles for MOOCs have been proposed for both on- and off-campus learning [7, $22,24,26,27,29]$; however, a clear rationale for their effective deployment is still nascent. This study focused on the use of a clinical anatomy MOOC by healthcare professionals building on previous research that analysed its use by undergraduate medical students [7]. It focused on the demographic profile of healthcare professionals who had voluntarily enrolled onto the MOOC, as well as attempting to establish the patterns of engagement, motivation and self-perceived benefits.

\section{Demographic Profile of Healthcare Learners}

The demographic distribution of healthcare professionals who completed the survey was broadly in line with the healthcare workforce of the UK, with females forming the majority $[47,48]$. This was evidenced with the majority of female learners identifying as either an allied healthcare professional or as a nurse, and male learners identifying as doctors. This distribution of gender is also in line with previous runs of the same MOOC, which highlighted a clear majority of female learners [7] and is consistent with the other courses developed by the University of Leeds [49] and those hosted more generally on the FutureLearn platform [50]. It should be noted, however, that these findings do differ from the global gender distribution of MOOC participation, which has a reportedly 2:1 ratio of male to female learners, although it is important to appreciate that platforms such as EdX and Coursera host a high number of courses which are predominantly male orientated $[21,51]$. Similarly, the healthcare professionals that enrolled were older than your typical MOOC learner, which has been reported to have a median age of less than 30 years old [21], although FutureLearn do note an older audience [50]. However, the pattern of employment and 
type of employment are similar to previously reported demographics and although it is unsurprising that the targeted individuals have a high-level of education, it does provide further evidence that MOOCs are attracting learners who are employed, educated and of a high socioeconomic status [21,52].

\section{Patterns of Engagement with the Anatomy MOOC}

Although the survey data indicates a majority of healthcare professionals were employed as AHPs, treated as a homogenous cohort, the level of engagement compared to undergraduate student engagement was noticeably different [7]. The undergraduates appeared to use the resources within the MOOC in a more personalised manner: They tended to enter the course, access the resources deemed useful and then leave. The healthcare professionals, however, appeared to behave in a much less personalised manner. They enrolled onto the course without prompting and then engaged in a much more ordered way. They closely followed the suggested course pathway and engaged in the core and clinically relevant material. Noticeably, they did not access the advanced material to a similar level as the undergraduate students, highlighting a clear disparity in engagement that could be related to the individual needs of the learner. The healthcare professionals also accessed the course more regularly, spending longer periods of time per visit. These contrasting levels of, and approaches to, engagement is not overly surprising when viewed within the specific context of each learner. A campus-based medical student is situated within a highly scaffolded curriculum, where they are presented with teacher-led sessions and immersed within a curriculum at that point in time. In this campus-based undergraduate setting, the MOOC served as a supplementary learning resource alongside the timetabled lectures, practical classes and tutorial sessions. It is therefore not unexpected that they approached the MOOC in a much more personalised manner, accessing the content they felt would supplement their existing resources. For the healthcare professionals, the main driver appeared to be a desire to learn new things, specifically in relation to their clinical practice, and as a result they tended to engage with the course more holistically. Without access to an alternative framework to focus their learning, each healthcare professional had to make their own decision as to what was important to them individually, and it is therefore understandable that this cohort would follow the course pathway more closely.

MOOCs are characterised by their openness and provide learners with an opportunity to discuss content amongst themselves in an online setting. This feature of the course did not appear to be generally appreciated by the healthcare professionals, who exhibited a low level of engagement that was similar to the undergraduate students use. However, it must be noted that although the willingness to share information amongst themselves may be questioned due to the low-level approval of the discussion fora, the figures reported are actually higher than for the general population who took the MOOC. Out of the total number of general learners who enrolled on the MOOC, only $17.6 \%$ posted at least one comment, with a large proportion of these, $37.2 \%$, posting just one. Furthermore, MOOCs in general have a low proportion of learners making comments, with FutureLearn reporting that only $36 \%$ of its learners engage in social interaction [53]. Although the massive nature of MOOCs may not lend itself to such discursive situations, the shift towards closed groups within MOOC platforms or small private online courses (SPOCs) may remedy such issues [54]. Such environments would promote the sharing of information amongst specialties in a targeted and informal online setting, providing opportunities that are not currently available. Situations could be envisaged where groups of like-minded healthcare professionals from a variety of disciplines could aggregate on such a course and participate together in an interprofessional setting, in contrast to the more traditionally situated IPE environments [55]. With the increased drive to incorporate IPE into medical curricula, and with clinical anatomy remaining a cornerstone of clinical practice, utilising a learning platform like a MOOC or SPOC offers new opportunities that are worthy of further exploration. Moreover, recent studies have highlighted how IPE undertaken with anatomy as a central focus can promote the team building and cultural shift required to work in a modern team-based healthcare system [56, 57]. Furthemore, with the contextual learning that IPE offers, anatomy knowledge itself can be enhanced as the content is given immediate relevance which supports its retention [58, 59]. Whether these positive outcomes of IPE within anatomy can be transposed to an online setting, such as a MOOC, remains unclear.

\section{Self-Perceived Benefits of Enrolling onto the Anatomy MOOC}

The self-perceived benefits of having enrolled onto the course are very clear, with the vast majority of healthcare professionals confirming that the course advanced their understanding of anatomy, with the majority reporting they feel able to work with increased confidence and competence. Although these conclusions are drawn from a group who were clearly highly motivated, as they not only enrolled on the MOOC, but also completed the survey, there is no reason to doubt their responses. Moreover, in regard to the healthcare profession in general, these benefits provide evidence as to the potential role for MOOCs as an effective CPD tool in medical education, either in isolation as an individual learner or part of an informal IPE environment. The value and perceived benefit of MOOCs is often questioned; however, the qualitative data presented within this paper provides a clear and 
unabridged view of the tangible benefits individuals have reported by engaging. In an era of individualisation and personalisation, this MOOC has provided a group of healthcare professionals an opportunity to either learn, or refresh their knowledge, and obtain a greater understanding of clinical anatomy which for them improves their practice, and for patients, enhances the quality of care received. With the vast amount of data and statistics that are generated on MOOCs, actually trying to draw out the benefits to individual learners and the wider public under their influence is a challenge. However, as Veletsianos [45] highlights, amongst the big data, it is those invisible learners who are undertaking an individual journey, which would previously have been unavailable, that MOOCs may serve. For some learners, this experience may be rather inconsequential, but for others, there may be a lasting impact on their own personal development, the students they teach, or the patients they treat. Examples have been provided previously as to how MOOCs can have a powerful impact on individuals [45], and much more work is needed to evidence the actual linkage between MOOCs as a CPD or IPE tool and patient outcomes. However, amongst all the conjecture and rhetoric on the value of MOOCs in education, the work highlighted in this paper adds empirical evidence to the nascent research in this field.

\section{Study Limitations and Future Directions}

The limitations of the study are primarily in the small sample size and the potential sampling bias. As the study uses data derived from a self-reported questionnaire, it is difficult to draw conclusions which can be generalised to other contexts. Moreover, the small sample size leaves interpretation of demographic profile, engagement patterns, and self-perceived benefits open to criticism. A final limitation is with the data only reflecting the use of a single MOOC created by one institution. However, due to the lack of empirical evidence into the utility of MOOCs in medical education, especially as a potential CPD tool for IPE, this data adds much needed research to this field.

Future research will endeavour to explore the potential role of clinical anatomy MOOCs within medical education. As this study has provided an exploratory view of the potential MOOCs can have as a CPD tool, further work will consider how more discussion can be created between healthcare professionals using either specific groupings within MOOCs or converting the current clinical anatomy MOOC into a SPOC. Only by understanding the boundaries to engaging fully with the discussion fora between individuals will the ability of MOOCs to be used as an approach to IPE, at either the undergraduate or postgraduate level, be fully appreciated. By targeting the MOOC to groups of specific healthcare individuals, and using more sophisticated qualitative and quantitative approaches, the role of MOOCs can be better understood.

\section{Conclusions}

The role of MOOCs in medical education is currently under explored. This study has attempted to provide an insight into the potential benefit that this mode of online learning can have on healthcare professionals as a form of CPD. This 3-week anatomy MOOC, developed by the University of Leeds, UK, attracted a number of healthcare professionals from a range of diverse roles and appeared to provide clear benefit. In comparison to undergraduate use of the same MOOC, the healthcare workers appeared to interact with the course in a more holistic way by following the suggested course pathway and clearly appreciated the diverse content available. Although the data presented suggests a lack of interaction with the discussion elements of the course, the level presented is relatively high compared to other courses and may potentially present an opportunity for their further use as a form of IPE. This could be achieved by the adaptation of the existing content into SPOCs, which can be specifically targeted at healthcare professionals. Due to the current lack of empirical evidence to support the development of a conceptual framework for the integration of MOOCs in medical education across all levels of training, this paper adds to this nascent field.

Acknowledgements The authors would also like to acknowledge the contribution made by the University of Leeds' Digital Learning Team, the numerous clinical staff involved in creating content and the graduate tutors who supported the delivery of the course. The authors would like to acknowledge Dr. Viktoria Joynes for providing helpful comments on draft versions of this paper.

\section{Compliance with Ethical Standards}

Conflict of Interest The authors have no conflicting interests between themselves, the Institution or FutureLearn; there is no financial arrangement between the Institution and FutureLearn.

Open Access This article is distributed under the terms of the Creative Commons Attribution 4.0 International License (http:// creativecommons.org/licenses/by/4.0/), which permits unrestricted use, distribution, and reproduction in any medium, provided you give appropriate credit to the original author(s) and the source, provide a link to the Creative Commons license, and indicate if changes were made.

\section{References}

1. Head K. Are MOOCs the future of general education. J Gen Educ. 2014;63(4):244-55.

2. Zemsky R. With a MOOC MOOC here and a MOOC MOOC there, here a MOOC, there a MOOC, everywhere a MOOC MOOC. J Gen Educ. 2014;63(4):237-43.

3. Laurillard D. The educational problem that MOOCs could solve: professional development for teachers of disadvantaged students. Res Learn Technol. 2016;24(1063519):1-17. 
4. Kellogg S. Online learning: how to make a MOOC. Nature. 2013;499:369-71.

5. Bateman J, Davies D. The challenge of disruptive innovation in learning technology. Med Educ. 2014;48(3):227-8.

6. Subhi Y, Andresen K, Rolskov Bojsen S, Mørkeberg Nilsson P, Konge L. Massive open online courses are relevant for postgraduate medical training. Dan Med J. 2014;61(10):A4923.

7. Swinnerton BJ, Morris NP, Hotchkiss S, Pickering JD. The integration of an anatomy massive open online course (MOOC) into a medical anatomy curriculum. Anat Sci Edu. 2016; doi:10.1002/ ase. 1625 .

8. Cook DA, Levinson AJ, Garside S, Dupras DM, Erwin PJ, Montori VM. Internet-based learning in the health professions: a meta-analysis. JAMA. 2008;300(10):1181-96.

9. Bass SA. Simple solutions to complex problems-MOOCs as a panacea? J Gen Educ. 2014;63(4):256-68.

10. Cook DA. The failure of e-learning research to inform educational practice, and what we can do about it. Med Teach. 2009;31(2):158-62.

11. Gillani N, Eynon R. Communication patterns in massively open online courses. Internet High Educ. 2014;23:18-26.

12. Schuwirth L, Van Der Vleuten C. Merging views on assessment. Med Educ. 2004;38(12):1208-10.

13. McLachlan JC. The relationship between assessment and learning. Med Educ. 2006;40(8):716-7.

14. Wormald BW, Schoeman S, Somasunderam A, Penn M. Assessment drives learning: an unavoidable truth? Anat Sci Educ. 2009;2(5):199-204.

15. Cilliers FJ. Is assessment good for learning or learning good for assessment? A. Both? B. Neither? C. It depends? Perspect Med Educ. 2015;4(6):280-1.

16. McAndrew P, Scanlon E. Open learning at a distance: lessons for struggling MOOCs. Science. 2013;342(6165):1450-1.

17. Milligan C, Littlejohn A. Supporting professional learning in a massive open online course. Int Rev Res Open Distrib Learn. 2014;15(5):197-213.

18. Hood N, Littlejohn A, Milligan C. Context counts: how learners' contexts influence learning in a MOOC. Comput Educ. 2015;91: 83-91.

19. Littlejohn A, Hood N, Milligan C, Mustain P. Learning in MOOCs: motivations and self-regulated learning in MOOCs. Internet High Educ. 2016;29:40-8.

20. Milligan $\mathrm{C}$, Littlejohn A. How health professionals regulate their learning in massive open online courses. Internet High Educ. 2016; doi:10.1016/j.iheduc.2016.07.005.

21. Glass CR, Shiokawa-Baklan MS, Saltarelli AJ. Who takes MOOCs? New Directions for Institutional Research. 2016;167: 41-55.

22. Prober CG, Heath C. Lecture halls without lectures - a proposal for medical education. N Engl J Med. 2012;366(18):1657-9.

23. Tucker B. The flipped classroom: online instruction at home frees class time for learning. Education Next. 2012;12:82-3.

24. Mehta NB, Hull AL, Young JB, Stoller JK. Just imagine: new paradigms for medical education. Acad Med. 2013;88(10):141823.

25. Bruff DO, Fisher DH, McEwen KE, Smith BE. Wrapping a MOOC: student perceptions of an experiment in blended learning. MERLOT J Online Learn Teach. 2013;9(2):187-99.

26. Kirch DG, Ast C. Interprofessionalism: educating to meet patient needs. Anat Sci Educ. 2014;8:296-8.

27. Harder B. Are MOOCs the future of medical education? BMJ. 2013;346:f2666.

28. Murphy K, Munk P. Continuing medical education: MOOCs (massive open online courses) and their implications for radiology learning. Can Assoc Radiol J. 64(3):165.
29. Liyanagunawardena TR, Williams SA. Massive open online courses on health and medicine: review. J Med Internet Res. 2014;16(8):e191.

30. Power A, Coulson K. What are OERs and MOOCs and what have they got to do with prep? Br J Midwifery. 2015;23(4):282-4.

31. Gandhi H. Technology to aid continuous professional development. Innovait Educ Inspir Gen Pract. 2013;7(4):241-6.

32. Reinders MEJ, de Jong PGM. Innovating clinical kidney transplant education by a massive open online course. Transpl Immunol. 2016; doi:10.1016/j.trim.2016.06.003.

33. Ghadiri K, Qayoumi MH, Junn E, Hsu P, Sujitparapitaya S (2013) The transformative potential of blended learning using MIT edX's $6.002 \mathrm{x}$ online MOOC content combined with student team-based learning in class. Environment 8:14.

34. Griffiths R, Mulhern C, Spies R, Chingos M. Adopting MOOCs on campus: a collaborative effort to test MOOCs on campuses of the university system of Maryland. Online Learn J. 2014;19:1-15.

35. Kearney RC, Premaraj S, Smith BM, Olson GW, Williamson AE, Romanos G. Massive open online courses in dental education: two viewpoints: viewpoint 1: massive open online courses offer transformative technology for dental education and viewpoint 2: massive open online courses are not ready for primetime. J Dent Educ. 2016;80:121-7.

36. GMC (2016) Guidance on CPD http://www.gmc-uk.org/education/ continuing_professional_development/cpd_guidance.asp. Accessed 22 June 2016.

37. McKeown PP, Heylings DJ, Stevenson M, McKelvey KJ, Nixon JR, McCluskey DR. The impact of curricular change on medical students' knowledge of anatomy. Med Educ. 2003;37:954-61.

38. Turney BW. Anatomy in a modern medical curriculum. Ann R Coll Surg Engl. 2007;89:104-7.

39. Drake RL, McBride JM, Lachman N, Pawlina W. Medical education in the anatomical sciences: the winds of change continue to blow. Anat Sci Educ. 2009;2:253-9.

40. Lachman N, Christensen KN, Pawlina W. Anatomy teaching assistants: facilitating teaching skills for medical students through apprenticeship and mentoring. Med Teach. 2013;35:e929-5.

41. Stringer MD, Lyall P. Design, implementation, and evaluation of a postgraduate diploma in surgical anatomy. Anat Sci Educ. 2012;5: $48-54$.

42. Louw G, Eizenber N, Carmichael SW. The place of anatomy in medical education: AMEE guide no 41*. Med Teach. 2009;31: 373-86.

43. Harden RM. Interprofessional education: the magical mystery tour now less of a mystery. Anat Sci Educ. 2015;8(4):291-5.

44. Thistlethwaite JE. Interprofessional education and the basic sciences: rationale and outcomes. Anat Sci Educ. 2015;8(4):299-304.

45. Veletsianos, G (2015) The Invisible Learners Taking MOOCs. Inside Higher Ed. http://www.insidehighered.com/blogs/highered-beta/invisible-learners-taking-moocs. Accessed 27 September 2016.

46. Boone HN Jr, Boone DA (2012) Analyzing Likert data. J Ext 50: 2TOT2

47. Yar M, Dix D. Bajekal M (2006) socio-demographic characteristics of the healthcare workforce in England and Wales-results from the 2001 census. Health Stat Q. 2006;32:44-56.

48. ONS (2013) Full report-women in the labour market. The Office of National Statistics. http://webarchive.nationalarchives.gov.uk/ 20160105160709/http://www.ons.gov.uk/ons/dcp171776_328352. pdf. Accessed 28 September 2016.

49. Morris NP, Hotchkiss S, Swinnerton B. Can demographic information predict MOOC learner outcomes? In: Proceedings of the European Stakeholders Summit on Experience and Best Practices in and Around MOOCs (EMOOCs2015). Mons, Belgium; 2015 may 18-20. Mons, Belgium: Universite Catholique de Louvain; 2015. p. 199-207. 
50. Macleod H, Haywood J, Woodgate A, Alkhatnai M. Emerging patterns in MOOCs: learners, course design and directions. Tech Trends. 2015;59(1):56-63.

51. Emanuel EJ. Online education: MOOCS taken by educated few. Nature. 2013;503:342.

52. Baturay MH. An overview of the world of MOOCs. ProcediaSocial and Behavioral Sciences. 2015;174:427-33.

53. Sharples M (2016) Effective pedagogy at scale: social learning and citizen inquiry. In: Proceedings of the Third ACM Conference on Learning @ Scale.p. 339-40.

54. Pomerol J-C, Epelboin Y, Thoury C. MOOCs: design, use and business models. London: Wiley ; $2015.68 \mathrm{p}$

55. Cleveland B, Kvan T. Designing learning spaces for interprofessional education in the anatomical sciences. Anat Sci Educ. 2015;8(4):371-80.
56. Hamilton SS, Yuan BJ, Lachman N, Hellyer NJ, Krause DA, Hollman JH, Youdas JW, Pawlina W. Interprofessional education in gross anatomy: experience with first-year medical and physical therapy students at Mayo Clinic. Anat Sci Educ. 2008;1:258-63.

57. Fernandes AR, Palombella A, Salfi J, Wainman B. Dissecting through barriers: a mixed-methods study on the effect of interprofessional education in a dissection course with healthcare professional students. Anat Sci Educ. 2015;8:305-16.

58. Willhelmson N, Dahlgren LO, Hult H, Scheja M, Lonka K, Josephson A. The anatomy of learning anatomy. Adv Health Sci Educ Theory Pract. 2010;15:153-65.

59. Rawson KA, Thomas RC, Jacoby LL. The power of examples: illustrative examples enhance conceptual learning of declarative concepts. Educ Psychol Rev. 2015;27:483-504. 